\title{
Nguyên tắc bảo đảm pháp chế xã hội chủ nghĩa trong tố tụng hình sự nhìn từ thực tiễn hoạt động của các cơ quan có thẩm quyền tiến hành tố tụng ở thành phố Hải Phòng
}

\author{
Nguyễn Quốc Hùng* \\ Công an Thành phố Hải Phòng, số 2 Lê Đại Hành, Hồng Bàng, Hải Phòng, Việt Nam \\ Ngày nhận 25 tháng 8 năm 2018 \\ Chỉnh sửa ngày 15 tháng 9 năm 2018; Chấp nhận đăng ngày 28 tháng 9 năm 2018
}

\begin{abstract}
Tóm tắt: Nguyên tắc bảo đảm Pháp chế xã hội chủ nghĩa trong tố tụng hình sự được quy định tại Điều 7 Bộ luật Tố tụng hình sự (BLTTHS) năm 2015 thể hiện định hướng tổ chức, hoạt động tố tụng đối với quá trình giải quyết vụ án hình sự. Nguyên tắc này đòi hỏi phải thực hiện các bảo đảm để tăng cường pháp chế khi tiến hành các hoạt động tố tụng hướng tới mục đích xác định sự thật khách quan vụ án; tôn trọng, bảo vệ quyền con người bảo vệ trật tự pháp luật; bảo vệ quyền lợi ích của thể nhân, pháp nhân, nhà nước và xã hội. Bài viết này nghiên cứu nguyên tắc bảo đảm pháp chế xã hội chủ nghĩa (XHCN) trong tố tụng hình sự (TTHS) từ thực tiễn hoạt động tố tụng của các cơ quan có thẩm quyền tiến hành tố tụng (CQCTQTHTT), người có thẩm quyền tiến hành tố tụng (NCTQTHTT) ở thành phố Hải phòng trên cơ sở phân tích các quy định của pháp luật về nguyên tắc này. Kết quả nghiên cứu sẽ đưa ra một số đề nghị, biện pháp nhằm tăng cường bảo đảm pháp chế XHCN trong TTHS.
\end{abstract}

Từ khóa: Nguyên tắc, pháp chế, tố tụng hình sự, bảo đảm, thực thi pháp luật, Hải Phòng, cơ quan có thẩm quyền tiến hành tố tụng.

\section{Nội dung nguyên tắc bảo đảm pháp chế xã hội chủ nghĩa trong tố tụng hình sự theo Bộ luật tố tụng hình sự năm 2015}

Nguyên tắc "Bảo đảm pháp chế xã hội chủ nghĩa trong tố tụng hình sự" (Điều 7) được quy định đầu tiên trong hệ thống các nguyên tắc cơ bản, với tính chất là nguyên tắc hiến định, đặt nền tảng cho mọi hoạt động tố tụng hình sự

\footnotetext{
* ĐT.: 84-913375566.

Email: nguyenquochung69hp@gmail.com https://doi.org/10.25073/2588-1167/vnuls.4173
}

(TTHS), được thiết kế dựa trên nguyên tắc tập trung quyền lực của nhà nước pháp quyền XHCN. TTHS được coi là quan hệ công quyền, đòi hỏi mọi chủ thể TTHS, đặc biệt đối với cơ quan, người có thẩm quyền tiến hành tố tụng phải tự giác, nghiêm chỉnh tuân thủ quy định của pháp luật khi tiến hành tố tụng giải quyết vụ án. Nguyên tắc này chi phối các nguyên tắc khác, theo hướng hoặc cụ thể hóa nguyên tắc bảo đảm pháp chế trong hoạt động khởi tố, điều tra, truy tố, xét xử, thi hành án; hoặc làm cơ sở cho việc bảo đảm nguyên tắc pháp chế bằng 
cách đưa ra các quy định để các chủ thể TTHS tuân thủ trong các hoạt động giải quyết vụ án hình sự. Nguyên tắc bảo đảm pháp chế XHCN trong Luật TTHS Việt Nam phản ánh bản chất của Nhà nước Việt Nam là Nhà nước pháp quyền $\mathrm{XHCN}$, của nhân dân, do nhân dân và vì nhân dân, thể hiện tư tưởng chủ đạo đối với toàn bộ hoạt động TTHS ở chỗ làm cho quá trình TTHS trong thực tiễn (khởi tố, điều tra, truy tố, xét xử và thi hành án) được vận hành một cách trật tự, ổn định, thống nhất, đồng bộ và đạt hiệu quả cao, cũng như các cơ quan tiến hành tố tụng, những người tiến hành tố tụng và những người tham gia tố tụng trong khi thực hiện quyền và nghĩa vụ tố tụng phải triệt để tuân theo những quy định của pháp luật TTHS Việt Nam. Theo GS.TSKH Đào Trí Úc thì "khi mà quan hệ tố tụng chủ yếu là quan hệ quyền lự thì yêu cầu bảo đảm pháp chế đuợc đặt ra truớc hết và chủ yếu là đối với cơ quan có thẩm quyền tiến hành tố tụng và người có thẩm quyền tiến hành tố tụng" [3, tr.59], rồi sau đó mới đến các chủ thể khác của TTHS. Do vậy, Điều 7 BLTTHS năm 2015 quy định nguyên tắc bảo đảm pháp chế xã hội chủ nghĩa trong TTHS, như sau: "Mọi hoạt động tố tụng hình sự phải được thực hiện theo quy định của Bộ luật này. Không được giải quyết nguồn tin về tội phạm, khởi tố, điều tra, truy tố, xét xủ ngoài nhũng căn cú và trình tư, thủ tuc do Bộ luật này quy định".

Nguyên tắc bảo đảm pháp chế XHCN trong TTHS định hướng cho quá trình xây dựng và thực thi pháp luật trong mọi hoạt động tố tụng giải quyết vụ án. Trên phương diện những giá trị hiện thực đạt được, các nguyên tắc này bảo đảm quá trình tố tụng được tiến hành thống nhất với phương châm bảo vệ quyền con người, lợi ích hợp pháp của công dân, pháp nhân cũng như nâng cao vai trò, trách nhiệm của các cơ quan có thẩm quyền tiến hành tố tụng trong đấu tranh xử lí tội phạm. Mặt khác, bảo đảm pháp chế XHCN trong TTHS còn là bảo đảm hiệu quả thực tế của các văn bản pháp luật do Nhà nước ban hành. Pháp luật TTHS được ban hành chỉ có giá trị trên thực tế khi được tuân thủ đầy đủ, nghiêm chỉnh trong quá trình áp dụng pháp luật sẽ đáp ứng được yêu cầu, đòi hỏi của nhiệm vụ cách mạng của đất nước ở từng giai đoạn phát triển. Ngược lại, nếu pháp luật TTHS không được chấp hành nghiêm chỉnh sẽ làm mất đi giá trị điều chỉnh của nó, đồng thời các cơ quan có thẩm quyền tiến hành tố tụng không thực hiện được chức năng đấu tranh xử lí tội phạm của mình. Trong bất kì lĩnh vực nào thì pháp chế đều có nghĩa là bảo đảm tính hợp hiến, hợp pháp, nghiêm chỉnh thực hiện pháp luật. Trong tố tụng hình sự, tuân theo những căn cứ, thẩm quyền và trình tự, thủ tục tố tụng là yêu cầu số một" [3, tr.59].

Với quy định tại Điều 7 BLTTHS năm 2015, nguyên tắc bảo đảm pháp chế XHCN trong TTHS có những nội dung chính sau đây:

Thư nhất, hình thành hệ thống pháp luật TTHS đầy đủ, phù hợp với thực tiễn đấu tranh xử lí tội phạm, với điều kiện phát triển đất nước bảo đảm hiệu quả, công bằng, dân chủ trong TTHS làm cơ sở cho việc tuân theo pháp luật triệt để trong TTHS. Các hoạt động tố tụng; trình tự, thủ tục khởi tố, điều tra, truy tố, xét xử và thi hành án hình sự; chức năng nhiệm vụ, quyền hạn và mối quan hệ giữa các cơ quan có thẩm quyền tiến hành tố tụng; quyền và nghĩa vụ của những người tham gia tố tụng và của các cơ quan nhà nước, tổ chức xã hội và công dân phải được quy định trong luật TTHS. Những quy định này phải cụ thể, rõ ràng, phù hợp với thực tế và không mâu thuẫn, chồng chéo, có như vậy các quy định đó của luật TTHS trở thành cơ sở vững chắc cho các hoạt động TTHS;

Thư hai, đòi hỏi việc thực hiện pháp luật nghiên chỉnh, tự giác, đầy đủ trong quá trình giải quyết vụ án hình sự của các chủ thể TTHS, mà trước hết là cơ quan, người có thẩm quyền tiến hành tố tụng. Mục đích giải quyết vụ án theo hướng phát hiện nhanh chóng, xử lí công minh, kịp thời mọi hành vi phạm tội, không để 
lọt tội phạm và không làm oan người vô tội chỉ có thể đạt được khi có sự chấp hành một cách tự nguyện, triệt để pháp luật TTHS của các chủ thể. Nhiệm vụ tuân thủ pháp luật tố tụng hình sự trước hết thuộc về các cơ quan tiến hành tố tụng và những người tiến hành tố tụng vì mọi hoạt động của họ đều đại diện cho Nhà nước và có ảnh hưởng nghiêm trọng tới việc giải quyết vụ án cũng như đến các quyền, lợi ích hợp pháp của công dân. Việc triệt để tuân theo pháp luật của những người tham gia tố tụng là cơ sở để các cơ quan tiến hành tố tụng bảo vệ các quyền và lợi ích hợp pháp của họ đồng thời đó cũng là nghĩa vụ mà họ phải tuân theo. Đồng thời, cũng đòi hỏi cơ chế thực thi pháp luật đồng bộ, có hiệu quả bảo đảm các cơ quan có thẩm quyền tiến hành tố tụng không những thực hiện tốt các chức năng tố tụng của mình mà còn có sự phối hợp nhịp nhàng giữa các cơ quan đó hướng tới mục tiêu chung của công cuộc đấu tranh phòng ngừa tội phạm.

\section{Bảo đảm pháp chế xã hội chủ nghĩa trong hoạt động tố tụng hình sự ở các cơ quan có thẩm quyền tiến hành tố tụng ở thành phố Hải Phòng}

\section{a. Tình hình và kêt quả xử lí tội phạm của các co quan có thẩm quyền tiến hành tố tụng ${ }^{\circ}$. thành phố Hải Phòng}

Hải Phòng là thành phố đô thị trung tâm loại I cấp quốc gia, một trong ba đỉnh của tam giác kinh tế trọng điểm miền Bắc (Hà Nội - Hải Phòng - Quảng Ninh) đang trong quá trình xây dựng trở thành thành công nghiệp phát triển hàng đầu đất nước mà mũi nhọn là sản xuất sản phẩm xuất khẩu và kinh tế biển. Do đặc điểm kinh tế, xã hội của thành phố năng động, phát triển có vị trí trung tâm tam giác phát triển kinh tế, đầu mối giao thông và cửa ngõ của vùng đồng bằng bắc bộ trong giao thương quốc tế thông qua cảng biển nên tình hình an ninh, trật tự xã hội có diễn biến khá phức tạp. Theo báo cáo của VKSNDTP Hải Phòng, trong thời gian qua, tình hình tội phạm diễn biến hết sức phức tạp. Năm 2013 khởi tố 1686 vụ án hình sự tăng 94 vụ bằng 5,9\% so với năm 2012; năm 2014 khởi tố là 1704 vụ, tăng 18 vụ bằng $1 \%$ so với năm 2013; năm 2015 khởi tố là 1733 vụ, tăng 29 vụ bằng 1,67\% so với năm 2014; năm 2016 khởi tố là 1834 vụ, tăng 101 vụ bằng $5,8 \%$ so với năm 2015; năm 2017 khởi tố là 1644 vụ, giảm 190 vụ bằng $10,3 \%$ so với năm 2016; Trong đó, nhiều loại tội phạm nguy hiểm tăng như các tội phạm về ma túy, giết người, hiếp dâm trẻ em, cướp tài sản và các tội gây rối trật tự công cộng, hủy hoại tài sản gây hậu quả nghiêm trọng. Hình thức phạm tội của các đối tượng ngày càng tinh vi hơn, sử dụng các loại vũ khí nguy hiểm đặc biệt là nhiều loại vũ khí do Trung Quốc sản xuất được lưu hành trái phép trên địa bàn thành phố nhưng qua công tác giám định lại không phải là vũ khí quân dụng: col xoay, col bas... Tính chất tội phạm ngày càng nguy hiểm hơn, có nhiều đối tượng đồng phạm hơn... [1].

Tội phạm về lĩnh vực trật tự xã hội, số vụ án đã phát hiện khởi tố từ năm 2013 đến năm 2016 có chiều hướng tăng, diễn biến phức tạp cả về tính chất, mức độ, thủ đoạn phạm tội... nhiều vụ án gây hậu quả đặc biệt nghiêm trọng. Điển hình là vụ Nguyễn Dũng Giang phạm tội giết người, các tội phạm xâm phạm tình dục trẻ em gia tăng. Trong năm 2011 xảy ra vụ án vi phạm các quy định về phòng cháy chữa cháy gây hậu quả đau thương, tang tóc làm 13 người chết, 25 người bị bỏng nặng và thiệt hại khoảng 800 triệu đồng. Tội phạm về kinh tế, chức vụ: số vụ án đã phát hiện khởi tố chủ yếu trong lĩnh vực tài chính, đất đai... về các tội tham ô, lợi dụng chức vụ quyền hạn chiếm đoạt tài sản, cố ý làm trái các quy định của Nhà nước gây hậu quả nghiêm trọng, lưu hành tiền giả, buôn bán hàng hóa qua biên giới, trốn thuế, vi phạm các quy định về quản lí đất đai... Điển hình là vụ vi phạm quản lí nhà nước về đất đai ở Đồ Sơn và xã Tú Sơn - Kiến Thụy. Tội phạm về hoạt động tư pháp: số vụ án đã phát hiện khởi tố từ 
năm 2013 đến năm 2017 có số lượng ít và có chiều hướng giảm; chủ yếu là tội trốn khỏi nơi giam; năm 2014 có 01 vụ buôn lậu, đưa và nhận hối lộ [2].

b. Một số uu điểm trong việc bảo đảm pháp chế XHCN trong hoạt động TTHS ở các co quan có thẩm quyền tiến hành tố tụng thành phố Hải Phòng

Kết quả giải quyết các vụ án hình sự nêu trên phản ánh rõ nét nhất mức độ thực hiện nguyên tắc bảo đảm pháp chế XHCN trong TTHS, có thể đưa ra một số nhận xét sau:

Thư nhất, các vụ án hình sự được các cơ quan có thẩm quyền tiến hành tố tụng thành phố Hải Phòng giải quyết theo đúng trình tự, thủ tục luật định.

Luật TTHS là luật hình thức nhằm giải quyết vụ án hình sự trên cơ sở luật hình sự (luật nội dung). Khi xác định có hành vi phạm tội do Bộ luật hình sự quy định, các cơ quan tiến hành tố tụng bắt tay vào việc tìm ra cơ chế, tính chất, mức độ của hành vi phạm tội bằng các biện pháp do pháp luật quy định. Vì vậy, quá trình giải quyết vụ án diễn ra theo tuần tự các bước, các giai đoạn mà trong luật học gọi là trình tự, thủ tục. Nếu không tuân theo các trình tự, thủ tục này thì coi như vụ án được giải quyết không hợp pháp. Nhìn chung, các vụ án hình sự đều tuân thủ nghiêm ngặt thủ tục tố tụng do BLTTHS năm 2003 quy định. Khi các cơ quan có thẩm quyền tiến hành tố tụng áp dụng các thủ tục tố tụng vào giải quyết vụ án hình sự cụ thể đã có ý thức chấp hành nghiêm chỉnh đầy đủ các quy định của pháp luật, nhất là các quyết định ảnh hưởng tới quyền và tự do của con người. Việc vi phạm thủ tục tố tụng chiếm số lượng không nhiều và được kiểm tra, giám sát phát hiện sớm, uốn nắn kịp thời. Đặc biệt, quá trình tiến hành TTHS có sự kiểm soát chặt chẽ của Viện Kiểm sát và các tổ chức hữu quan khác nên các biểu hiện vi phạm pháp luật trong quá trình tố tụng về cơ bản được khắc phục nhanh chóng.
Thư hai, các vụ án được giải quyết nhanh gọn, đảm bảo thời hạn tố tụng.

Tiến độ giải quyết án cũng nói lên trình độ, khả năng của cơ quan tiến hành tố tụng và người tiến hành tố tụng. Vì thế, thời hạn được luât TTHS quy định yêu cầu cơ quan, người có thẩm quyền tiến hành tố tụng phải hoàn thành công việc nhiệm vụ tố tụng. Thời hạn ràng buộc trách nhiệm của cơ quan tiến hành tố tụng nhưng đồng thời cũng là quyền lợi của người bị cáo buộc phạm tội và những người tham gia tố tụng khác do đó các cơ quan có thẩm quyền tiến hành tố tụng của thành phố đã chấp hành nghiêm chỉnh thời hạn tố tụng theo quy định của pháp luật. Đối với những vụ án có tính chất phức tạp, mức độ nguy hiểm lớn cho xã hội thì thời hạn điều tra, truy tố, xét xử được người đứng đầu các cơ quan có thẩm quyền tiến hành tố tụng chỉ đạo, yêu cầu người trực tiếp tiến hành tố tụng tập trung giải quyết nên phần lớn các vụ án hình sự được giải quyết trong thời hạn cho phép.

Thứ $b a$, quyền con người, lợi ích của cá nhân, pháp nhân tham gia tố tụng được bảo đảm.

Xu hướng dân chủ hoá đời sống chính trịpháp lí của nhân loại ngày càng cao nên những đòi hỏi nhà nước bảo đảm quyền lợi cho họ là chính đáng. Điều này không những phù hợp với các Công ước quốc tế về quyền con người mà còn bảo đảm hiệu lực của các quy phạm pháp luật đã được pháp điển hoá. Bộ luật TTHS 2015 trên cơ sở kế thừa Bộ luật TTHS 2003 và tình hình kinh tế - chính trị đất nước thời kì đổi mới đã đưa ra một quy chế pháp lí khá toàn diện để các quyền lợi của người tham gia TTHS được bảo đảm.

Trong giải quyết các vụ án hình sự hiện nay, người tham gia tố tụng hoàn toàn có quyền làm những gì pháp luật không cấm. Vì vậy, họ có quyền đòi hỏi lợi ích chính đáng cho mình từ phía người phạm tội và các cơ quan nhà nước. Ngay cả người bị nghi đã thực hiện một tội phạm cũng có thể đưa ra lập luận để phủ nhận kết luận của các cơ quan tiến hành tố tụng mặc 
dù nghĩa vụ chứng minh thuộc về các cơ quan tiến hành tố tụng. Khi họ không yêu cầu bảo vệ quyền lợi thì từ phía các cơ quan tiến hành tố tụng cũng phải chủ động mời người bào chữa cho họ trong một số trường hợp nhất định theo Điều 57 BLTTHS năm 2015 bộ luật tố tụng hình sự 2015. Thủ tục mời người bào chữa trong những trường hợp này là bắt buộc, nếu không có sẽ dẫn đến sai lệch tố tụng và không đạt được các mục đích của chính sách pháp luật. Quyền lợi của người tham gia tố tụng được bảo đảm còn thể hiện ở quyền khiếu nại đối với hành vi tố tụng, quyết định tố tụng của các cơ quan tiến hành tố tụng, quyền kháng cáo đối với bản án của Toà án nếu họ thấy không thoả mãn và phát hiện có dấu hiệu vi phạm pháp luật. Các cơ quan tiến hành tố tụng cũng giải thích cơ sở pháp lí rõ ràng để họ thực hiện được quyền này. Trên thực tế, người tham gia tố tụng đã sử dụng quyền này một cách triệt để khi có các bản án phúc thẩm đã sửa hoặc huỷ án sơ thẩm. Điều này càng khẳng định tính khách quan và toàn diện khi xét xử các vụ án hình sự cũng như nâng cao quyền tự do dân chủ của công dân.

c. Nhũng hạn chế trong việc bảo đảm pháp chế xã hội chủ nghĩa trong hoạt động tố tụng hình sư ở các cơ quan có thẩm quyền tiến hành tố tụng ở thành phố Hải Phòng

Bên cạnh những mặt được, ưu điểm nêu trên trong các quá trình tiến hành tố tụng giải quyết vụ án còn bộc lộ hạn chế, bất cập của các cơ quan có thẩm quyền tiến hành tố tụng, vẫn còn để lọt tội phạm, làm oan người vô tội và vi phạm pháp luật khi giải quyết vụ án hình sự. Hạn chế, bất cập đó được biểu hiện ở những khía canh sau:

Thư nhất, nhận thức về các quy định của pháp luật chưa đầy đủ, thống nhất nên việc thực hiện, áp dụng khi giải quyết vụ án dẫn đến sai xót, vi phạm. Các quy định của pháp luật Hình sự, luật Tố tụng hình sự và những quy định của pháp luật khác có liên quan là cơ sở để các cơ quan có thẩm quyền tiến hành tố tụng thực thi, áp dụng trong quá trình giải quyết vụ án. Vì vậy, nhận thức đúng đắn, chính xác quy định của pháp luật là yêu cầu quan trọng đầu tiên đối với các cơ quan, người có thẩm quyền tiến hành tố. Thực tiễn hoạt động giải quyết vụ án ở thành phố Hải Phòng cho thấy đã có nhận thức khác nhau của quy định pháp luật về cùng một vấn đề nên dẫn đến kết luận, quyết định tố tụng của Cơ quan điều tra và Viện Kiểm sát, Tòa án mâu thuẫn nhau. Chẳng hạn: Theo khoản 3 điều 110 BLTTHS năm 2015 quy định về thẩm quyền điều tra của Viện Kiểm sát: "Cơ quan điều tra của Viện Kiểm sát Nhân dân Tối cao điều tra một số loại tội xâm phạm hoạt động tư pháp mà người phạm tội là cán bộ thuộc các cơ quan tư pháp". Thành thử ra Viện Kiểm sát giữ chức năng thực hành quyền công tố và kiểm sát điều tra các vụ án hình sự mà lại trực tiếp điều tra thì làm sao có thể phát hiện ra được vi phạm trước kết luận điều tra của chính mình. Bất cập này dẫn đến hậu quả tất yếu có ngoại lệ trong thực hiện chức năng vì thẩm quyền điều tra không có sự chuyên biệt. Hoặc BLTTHS năm 2015 cũng quy định khá rõ thẩm quyền khởi tố vụ án của cơ quan tiến hành tố tụng. "Viện Kiểm sát ra quyết định khởi tố vụ án hình sự trong trường hợp Viện Kiểm sát huỷ bỏ quyết định không khởi tố của các cơ quan quy định tại khoản này và trong trường hợp Hội đồng xét xử yêu cầu khởi tố vụ án. Hội đồng xét xử ra quyết định khởi tố hoặc yêu cầu Viện Kiểm sát khởi tố vụ án hình sự nếu qua việc xét xử tại phiên toà mà phát hiện được tội phạm hoặc người phạm tội mới cần phải điều tra". Đến đây, những quy định này cũng chứa đựng những mâu thuẫn. Viện Kiểm sát thì khởi tố khi cơ quan điều tra không khởi tố hoặc Hội đồng xét xử yêu cầu khởi tố, vậy chức năng của Viện Kiểm sát là gì? Giữa hai mảng điều tra và xét xử, Viện Kiểm sát đều có quyền giám sát việc tuân theo pháp luật của Cơ quan điều tra và Toà án nhưng không có nghĩa vụ phải làm thay việc cho hai cơ quan này. Quy định của pháp luật về thẩm quyền khởi tố của Viện Kiểm sát không nằm 
ngoài mục đích là để phát hiện triệt để các hành vi phạm tội nhưng không vì thế mà phải ôm đồm công việc của các cơ quan khác. Còn về thẩm quyền khởi tố của Toà án đối với tội phạm mới phát hiện tại phiên toà cũng lại là bất cập. Chỉ duy nhất Toà án mới có quyền kết luận một người có tội hay không có tội bằng bản án hoặc quyết định có hiệu lực pháp luật. Trên thực tế, mặc dù có quyết định khởi tố, kết luận điều tra của Cơ quan điều tra, Cáo trạng của Viện Kiểm sát là bị cáo có tội nhưng Toà án vẫn có thể tuyên bị cáo vô tội. Quyết định tuyên án vô tội của toà án có giá trị pháp lí cao nhất, có thể phủ nhận quan điểm của Cơ quan điều tra và Viện Kiểm sát. Vì thế, nếu Tòa án cũng được quyền khởi tố vụ án hình sự đối với tội phạm mới thì liệu khi xét xử có bảo đảm tính công bằng và đúng pháp luật hay không. Khó có chuyện Toà án "tuyên vô tội" đối với tội phạm mà mình đã khởi tố vì chẳng khác nào Toà án vừa đưa ra vấn đề và tự giải quyết vấn đề theo quan điểm của mình. Điều này dẫn đến sự không vô tư và khách quan trong các hoạt động tố tụng của Toà án và làm giảm vai trò của Cơ quan điều tra, Viện Kiểm sát trong điều tra, truy tố vụ án.

Thư hai, còn có những vi phạm trong việc bảo vệ quyền con người, quyền và lợi ích hợp pháp của người bị cáo buộc phạm tội, bị can, bị cáo và những người tham gia tố tụng khác của cơ quan người có thẩm quyền tiến hành tố tụng trong quá trình tố tụng giải quyết vụ án. Người bị cáo buộc phạm tội, bị can, bị cáo là đối tượng chính của vụ án vì từ họ mới phát sinh các quan hệ pháp luật tố tụng hình sự, phát sinh tội phạm và gây thiệt hại đến các quan hệ xã hội được luật hình sự bảo vệ. Bên cạnh nhiệm vụ phải điều tra tìm ra sự thật của vụ án để áp dụng các biện pháp cưỡng chế nhà nước nghiêm khắc nhất đối với hành vi của họ thì pháp luật vẫn có những quy định để bảo vệ quê̂̀n lợi cho họ phù hợp với các quyền cơ bản của công dân trong hoạt động tố tụng hình sự theo pháp luật quốc tế và pháp luật quốc gia. Vì vậy, trong quá trình tiến hành tố tụng cơ quan, người có thẩm quyền tiến hành tố tụng phải có trách nhiệm tôn trọng bảo đảm quyền con người của họ theo quy định của pháp luật. Tuy nhiên, trong quá trình tố tụng các cơ quan, người có thẩm quyền tiến hành tố tụng còn có những vi phạm, như: Chưa thực sự bảo đảm, tạo điều kiện để người bị cáo buộc phạm tội thực hiện đầy đủ quyền bào chữa mà pháp luật quy định cho họ. Chẳng hạn: trên thực tế, việc luật sư được gặp bị can đang bị tạm giam còn gặp nhiều khó khăn, nhiều trường hợp bị từ chối với lí do điều tra viên đi công tác hay những lí do thiếu thuyết phục khác; hoặc thông báo thời gian quá gấp khiến luật sư không thể thu xếp để tham gia cuộc hỏi cung được...

Hoặc vi phạm về quyền của người làm chứng, mặc dù họ có vai trò quan trọng hỗ trợ cơ quan có thẩm quyền tiến hành tố tụng trong việc điều tra chứng minh làm rõ tội phạm. Trên thực tế, việc người làm chứng được bảo vệ tính mạng, sức khoẻ, danh dự, nhân phẩm, tài sản và các quyền, lợi ích hợp pháp khác của mình khi tham gia tố tụng thường bị các cơ quan tiến hành tố tụng coi nhẹ, chưa có các biện pháp thực tế bảo đảm quyền này cho họ, đồng thời quyền được cơ quan triệu tập thanh toán chi phí đi lại và những chi phí khác theo quy định của pháp luật cũng chưa được thực hiện một cách đầy đủ do khó khăn về quy định của pháp luật cũng như nguồn kinh phí áp dụng.

Trong quá trình giải quyết vụ án hình sự, các CQCTQTHTT và NCTQTHTT được quyền áp dụng các biện pháp ngăn chặn, biện pháp điều tra thu thập chứng cứ và những biện pháp cưỡng chế khác bảo đảm cho việc giải quyết vụ án. Khi áp dụng các biện pháp này cơ quan và người có thẩm quyền nhất thiết phải tuân theo các quy định của Luật TTHS về căn cứ áp dụng, thẩm quyền, trình tự, thủ tục và quy định khác của các biện pháp đó. Tuy nhiên, thực tiễn giải quyết vụ án cho thấy đã có những vi phạm như:

Không có người làm chứng khi áp dụng biện pháp bắt người nhất là việc bắt người trong trường hợp khẩn cấp, có trường hợp cơ quan điều tra khi tiến hành lệnh bắt người trong 
trường hợp khẩn cấp vào ban đêm tại khu vực vắng người, do việc bắt cần bảo đảm an toàn nên cán bộ tiến hành bắt đối tượng đưa ngay về trụ sở nên khi lập biên bản lại chủ quan không có người làm chứng.

Vi phạm thời hạn tạm giữ, tạm giam thường rơi vào trường hợp do cách hiểu luật chưa chính xác nên lúng túng trong việc tính thời hạn tạm giữ 3 ngày được xác định từ khi ra quyết định tạm giữ hay từ khi cơ quan điều tra lập biên bản bắt người trong trường hợp khẩn cấp hoặc phạm tội quả tang do đó dẫn đến tình trạng vi phạm thời hạn tạm giữ. Hoặc việc điều tra viên, kiểm sát viên chủ quan không theo dõi sát thời hạn tạm giữ, tạm giam nên dẫn đến tình trạng chưa kịp thời gia hạn tạm giữ, tạm giam do đó vi phạm thời hạn tạm giữ, tạm giam.

Hạn chế nêu trên một phần là nguyên nhân làm cho việc giải quyết vụ án thiếu khách quan và do đó pháp chế không thể được bảo đảm vì vẫn tồn tại nguy cơ xảy ra oan, sai hoặc bỏ lọt tội phạm.

Thư $b a$, vi phạm thẩm quyền, thủ tục, thời hạn ở các giai đoạn tố tụng giải quyết vụ án. Luật TTHS là luật về hình thức nên đòi hỏi mọi quy định về thẩm quyền, trình tự, thủ tục và thời hạn đều phải được thực hiện đúng, đầy đủ, mọi vi phạm đều dẫn đến hậu quả pháp lí làm cho các hành vi, quyết định tố tụng của các cơ quan, người có thẩm quyền tiến hành tố tụng không có giá trị pháp lí, sự thật khách quan vụ án không được làm rõ. Trong quá trình giải quyết vụ án, các vi phạm về thẩm quyền, thủ tục, thời hạn vẫn còn xảy ra ở tất cả các giai đoạn khởi tố, điều tra, truy tố, xét xử, thi hành án. Chẳng hạn: có trường hợp đồng chí thủ trưởng cơ quan điều tra nghỉ hưu, chưa có đồng chí bổ nhiệm mới, để kịp thời trong công tác điều tra, đồng chí phó thủ trưởng ký quyết định khởi tố vụ án hình sự và quyết định phân công điều tra viên.

Thư $t u$, một trong yếu tố bảo đảm pháp chế XHCN trong TTHS là việc thường xuyên kiểm tra, giám sát, kiểm sát kịp thời phát hiện các vi phạm, sai lầm trong quá trình tố tụng giải quyết vụ án. Tuy nhiên, thực tiễn hoạt động tố tụng ở thành phố Hải phòng cho thấy: (i) Việc kiểm tra trong nội bộ mỗi CQCTQTHTT cũng như việc kiểm tra của CQCTQTHTT cấp trên đối với CQCTQTHTT của thành phố không phải lúc nào cũng được thường xuyên. Vì vậy, đã không kịp thời phát hiện những vi phạm của CQCTQTHTT, NCTQTHTT; (ii) Vai trò giám sát của Hội đồng nhân dân các cấp, của Mặt trận tổ quốc, các cơ quan, đoàn thể và nhân dân đối với hoạt động tố tụng giải quyết vụ án còn nhiều hạn chế nên đã ảnh hưởng đến việc thực nguyên tắc pháp chế XHCN trong hoạt động TTHS ở thành phố. Do nhận thức về công tác giám sát, về pháp luật hình sự và sự nể nang của Hội đồng nhân dân các cấp, của Mặt trận tổ quốc, các cơ quan, đoàn thể, đặc biệt là ở cơ sở và nhân dân nên việc tiến hành giám sát đối với hoạt động tố tụng còn qua loa, đại khái, việc giám sát chưa được thường xuyên và hiệu quả; (iii) Kiểm sát là chức năng, trách nhiệm của Viện Kiểm sát đối với việc bảo đảm tuân theo pháp luật trong suốt quá trình giải quyết vụ án từ khi khởi tố vụ án đến giai đoạn thi hành án. Thực tiễn thực hiện chức năng của Viện Kiểm sát Nhân dân hai cấp ở thành phố Hải Phòng cho thấy còn nhiều hạn chế, bất cập. Việc kiểm sát của Viện Kiểm sát nhân dân hai cấp ở thành phố Hải Phòng chưa chặt chẽ ngay từ khâu tiếp nhận thông tin từ CQĐT, nhất là sổ thụ lí; việc phối hợp cùng CQĐT phân loại thông tin, không để lọt tội phạm; đề ra yêu cầu xác minh đối với tố giác, tin báo về tội phạm và kiến nghị khởi tố chưa thực sự được chủ động; chất lượng yêu cầu xác minh chưa cao và việc giám sát, kiểm tra xem ĐTV có thực hiện hay không để có biện pháp giải quyết chưa thực hiện thường xuyên. Kiểm sát viên theo dõi thống kê còn chưa chủ động liên hệ với Cán bộ điều tra phụ trách thống kê của CQĐT để theo dõi tình hình giải quyết. Kiểm sát viên được phân công kiểm sát việc tiếp nhận, giải quyết tố giác, tin báo về tội phạm chưa thực sự chủ động liên hệ CQĐT để theo dõi tình hình xác minh, giải quyết; đôn đốc, nhắc nhở cán bộ điều tra, ĐTV đẩy nhanh tiến độ giải quyết. 


\section{Hướng tới việc tăng cường bảo đảm pháp chế xã hội chủ nghĩa trong hoạt động tố tụng hình sự của các cơ quan có thẩm quyền tiến hành tố tụng ở thành phố Hải Phòng}

Trên cơ sở phân tích các nguyên nhân của những hạn chế trong việc thực hiện nguyên tắc bảo đảm pháp chế XHCN trong hoạt động TTHS của các cơ quan có thẩm quyền tiến hành tố tụng thành phố Hải Phòng, tác giả đưa ra những kiến nghị nhằm tăng cường bảo đảm pháp chế trong quá trình tố tụng giải quyết vụ án, cụ thể như sau:

\section{a. Tăng cường công tác hoàn thiện, giải thich pháp luật}

Nguyên nhân đầu tiên, quan trọng dẫn đến những hạn chế của việc bảo đảm pháp chế XHCN trong TTHS là các quy định của pháp luật chưa thật sự phù hợp với thực tế giải quyết vụ án, với các điều kiện về kinh tế xã hội và với hệ thống pháp luật của đất nước. Thực tiễn hoạt động tố tụng cho thấy một số quy định của pháp luật còn có những mâu thuẫn, chẳng hạn: Quy định Viện kiểm sát bên cạnh chức năng thực hành quyền công tố lại còn có chức năng kiểm sát việc tuân thủ pháp luật trong quá trình giải quyết vụ án liệu có bảo đảm tính khách quan và tính hiệu quả trong việc kiểm soát hoạt động tố tụng không khi Viện kiểm sát lại kiểm sát đối với hoạt dộng của chính mình... Bên cạnh đó, BLHS năm 2015 và BLTTHS năm 2015 đã có hiệu lực thi hành nhưng việc giải thích, hướng dẫn thi hành chưa kịp thời gây khó khăn cho việc thực thi, áp dụng pháp luật trong quá trình giải quyết vụ án, chẳng hạn: Cả BLHS năm 2015 sửa đổi và BLTTHS năm 2015 đều quy định trách nhiệm hình sự và thủ tục truy cứu trách nhiệm hình sự đối với pháp nhân nhưng chưa có bất kì một hướng dẫn, giải thích nào...

Vì vậy, cần có định hướng, kế hoạch: (i) Tiếp tục hoàn thiện pháp luật hình sự, pháp luật TTHS theo hướng thể hiện đầy đủ chính sách hình sự của Đảng, Nhà nước trong thời kì đổi mới xây dựng đất nước; phù hợp với các điều kiện kinh tế - xã hội; Bảo đảm quyền con người; hội nhập quốc tế; (ii) Cần có các hướng dẫn giải thích BLHS năm 2015 và BLTTHS năm 2015 là cơ sở để các CQCTQTHTT thực hiện, áp dụng nghiêm chỉnh, đầy đủ trong quá trình giải quyết vụ án hình sự; (iii) Khi xây dựng các văn bản giải thích, hướng dẫn thi hành cần dựa trên kết quả của các nghiên cứu khoa học, tranh thủ ý kiến xã hội, nhất là cần có sự tham khảo ý kiến của các CQCTQTHTT ở các địa phương.

Với truyền thống và kinh nghiệm của mình các CQCTQTHTT thành phố Hải phòng tích cực tham gia vào quá trình hoàn thiện pháp luật và nhất là tham gia vào quá trình xây dựng các các văn bản giải thích, hướng dẫn thi hành luật góp phần vào việc bảo đảm pháp chế XHCN trong quá trình giải quyết vụ án hình sự.

b. Tăng cuờng công tác phổ biến, giáo dục pháp luật

Hệ thống pháp luật đầy đủ, toàn diện, phù hợp với thực tiễn và điều kiện kinh tế - xã hội mới chỉ là tiền đề, muốn bảo đảm pháp chế XHCN trong TTHS thì pháp luật cần được nhận thức đúng đắn, thống nhất trong cả nước, ở tất cả những NCTQTHTT trong các CQCTQTHTT. Vì vậy, tăng cường công tác phổ biến, giáo dục pháp luật, nhất là công tác tập huấn, bồi dưỡng để NCTQTHTT trong các CQCTQTHTT nhận thức đúng đắn, thống nhất pháp luật trong quá trình giải quyết vụ án hình sự. Công tác này cần được tiến hành kịp thời, thường xuyên liên tục bảo đảm tính cập nhật của các văn bản quy phạm pháp luật mới ban hành. Bên cạnh đó, cũng cần tăng cường công tác phổ biến, giáo dục cho các tầng lớp nhân dân, nhất là đối cán bộ, công chức trong các cơ quan nhà nước, Mặt trận tổ quốc và các đoàn thể để họ có điều kiện thực hiện trách nhiệm của mình theo quy định của pháp luật TTHS. Đồng thời, việc hiểu biết pháp luật TTHS còn giúp họ tự bảo vệ mình khi có liên quan đến tố tụng và thực hiện chức năng giám sát hoạt động tố tụng của các CQCTQTHTT và 
NCTQTHTT trong quá trình giải quyết vụ án hình sự.

Những năm vừa qua công tác này được các CQCTQTHTT thành phố Hải phòng quan tâm, tuy nhiên chất lượng phổ biến giáo dục pháp luật vẫn chưa được như mong muốn. Việc nhận thức đúng đắn pháp luật ở đội ngũ người CTQTHTT vẫn còn những bất cập để xảy ra những sai sót, vi phạm đáng tiếc do nhận thức khi tiến hành tố tụng giải quyết vụ án. Vì vậy, việc khắc phục cần được các CQCTQTHTT thành phố quan tâm, có kế hoạch cụ thề và có định hướng lâu dài.

\section{c. Hình thành cơ chế thực thi pháp luật hiệu quả}

Cơ chế thực thi pháp luật hiệu quả, đòi hỏi pháp luật TTHS phải được nhận thức và thực thi thống nhất trong tất cả mọi hoạt động ở các giai đoạn tố tụng của quá trình giải quyết vụ án của các chủ thể tố tụng mà trước hết là cơ quan, người có thẩm quyền tiến hành tố tụng. Chỉ có như vậy mục đích giải quyết vụ án theo hướng phát hiện nhanh chóng, xử lí công minh, kịp thời mọi hành vi phạm tội, không để lọt tội phạm và không làm oan người vô tội mới có thể đạt được. Nhiệm vụ tuân thủ pháp luật tố tụng hình sự trước hết thuộc về các cơ quan tiến hành tố tụng và những người tiến hành tố tụng vì mọi hoạt động của họ đều đại diện cho Nhà nước và có ảnh hưởng nghiêm trọng tới việc giải quyết vụ án cũng như đến các quyền, lợi ích hợp pháp của công dân. Việc triệt để tuân theo pháp luật của những người tham gia tố tụng là cơ sơ để các cơ quan tiến hành tố tụng bảo vệ các quyền và lợi ích hợp pháp của họ đồng thời đó cũng là nghĩa vụ mà họ phải tuân theo.

Thủ tục, trình tự tố tụng quy định cho các hoạt động TTHS ở các giai đoạn giải quyết vụ án đều phải chấp hành nghiêm chỉnh; mọi sự không tuân thủ đều bị coi là vi phạm và dẫn đến hệ quả pháp lí tiêu cực đối với các quyết định của cơ quan, người có thẩm quyền giải quyết vụ án hình sự. Chẳng hạn: Điều 245 , điểm $\mathrm{d}$, khoản 1 coi "vị phạm nghiêm trọng thủ tục tố tụng" là căn cứ để trả hồ sơ để điều tra bổ sung; hoặc khi "có vi phạm nghiêm trọng thủ tục tố tụng trong điều tra, truy tố, xét xử dẫn đến sai lầm nghiên trọng trong việc giải quyết vụ án" (Khoản 2 Điều 371) sẽ là căn cứ để kháng nghị theo thủ tục giám đốc thẩm đối với bản án, quyết định có hiệu lực pháp luật của tòa án... Vì vậy, cần xây dựng cơ chế thực thi pháp luật có hiệu quả trong quá trình tố tụng giải quyết vụ án.

d. Tăng cuờng công tác kiểm tra, giám sát trong việc thực thi pháp luật

Việc kiểm tra, giám sát đối với hoạt động TTHS đã được BLTTHS 2015 quy định thành cơ chế trên cơ sở nguyên tắc "kiểm tra, giám sát trong tố tụng hình sự" tại Điều 33 BLTTHS 2015, điều chỉnh hai nội dung kiểm tra và giám sát đối với hoạt động TTHS. Việc kiểm tra, giám sát trong TTHS là một trong những đảm bảo cho yêu cầu để tăng cường pháp chế XHCN là có sự kiểm tra, giám sát việc thi hành pháp luật. Vì vậy, việc kiểm tra, giám sát hoạt động tố tụng hình sự cần phải được tăng cường để pháp luật được thực thi nghiêm chỉnh trong quá trình giải quyết vụ án góp phần bảo đảm pháp chế XHCN trong TTHS.

\section{Tài liệu tham khảo}

[1] Viện Kiểm sát Nhân dân thành phố Hải Phòng, Báo cáo tổng kết các năm từ 2013 đến 2017.

[2] Công an thành phố Hải Phòng, Báo cáo thống kê các năm từ 2013 đến 2017.

[3] Đào Trí Úc, Hệ thống các nguyên tắc cơ bản của TTHS Việt Nam theo Bộ luật Tố tụng hình sự 2015 trong sách Những nội dung mới của Bộ luật Tố tụng hình sự 2015, do PGS.TS Nguyễn Hòa Bình chủ biên, NXB Chính trị Quốc gia, Hà Nội, năm 2016. 


\title{
Ensuring the Socialist Law in Criminal Procedure through Procedural Activities of the Proceedings - Conducting Agencies in Hai Phong City
}

\author{
Nguyen Quoc Hung \\ Hai Phong Public Security Department, 2 Le Dai Hanh, Hong Bang, Hai Phong, Vietnam
}

\begin{abstract}
The principle of ensuring the socialist law in criminal procedures is stipulated in Article 7 of Criminal Procedure Code 2015. That principle shows the orientation for the organization and operation of criminal proceedings in the process of settling criminal cases. This principle requires the implementation of assurances to strengthen legislation in the conduct of proceedings aimed at determining the objective truth of the case; respecting and protecting human rights; protecting the legal order; protecting the interests of natural persons, legal persons, the state and society. This article examines the principle of socialist legal assurances in criminal procedure from the procedural activities of the proceedings-conducting agencies in Hai Phong city based on the analysis of the provisions of the law on this principle. The results of the study provide suggestions and measures to ensure the socialist law in criminal procedure.
\end{abstract}

Keywords: Principle, legislation, crinminal procedure, law enforcement, Hai Phong city. 